\title{
FLAT PLATE PULSATING HEAT PIPES WITH DIFFERENT CHANNEL GEOMETRIES FOR HIGH HEAT FLUX APPLICATIONS
}

\author{
L. Krambeck, \\ K. G. Domiciano, \\ L. A. Betancur-Arboleda, \\ and M. B. H. Mantelli \\ Universidade Federal de Santa Catarina \\ Departamento de Engenharia Mecânica \\ LEPTEN/LABTUCAL \\ Bairro Trindade \\ CP. 88040-900, Florianópolis, Santa Catarina, \\ larissa.krambeck@labtucal.ufsc.br \\ kelvin.guessi@labtucal.ufsc.br \\ luisbetancur@labtucal.ufsc.br \\ marcia@labtucal.ufsc.br \\ Received: Nov 23, 2020 \\ Revised: Dec 31, 2020 \\ Accepted: Jan 08, 2021

\section{NOMENCLATURE}

$\begin{array}{ll}\text { FR } & \text { filling ratio, } \% \\ \text { q" } & \text { heat flux, } \mathrm{W} / \mathrm{m}^{2} \\ \mathrm{q} & \text { heat load, } \mathrm{W} \\ \mathrm{R}_{\mathrm{t}} & \text { thermal resistance, } \mathrm{K} / \mathrm{W} \\ \mathrm{T} & \text { temperature, }{ }^{\circ} \mathrm{C} \\ \overline{\mathrm{T}} & \text { average temperature, }{ }^{\circ} \mathrm{C} \\ \mathrm{t} & \text { time, } \mathrm{s}\end{array}$

Brasil

\section{ABSTRACT}

The thermal performance of flat plate pulsating heat pipes with different channel geometries was performed in this experimental work. The tests were accomplished with two channel profiles, round and grooved. One of the channel geometries, located on the evaporator, can be considered novel, consisting of a round channel with two lateral grooves. Diffusion bonding technology was used to manufacture the PHPs made of two copper flat plates. Distilled water was used as the working fluid with a filling ratio of $50 \%(17.9 \mathrm{ml})$ of the total volume. The pulsating heat pipes were tested at one position (vertical) under heat loads from 20 up to $2000 \mathrm{~W}$. The experimental results showed that both flat plate pulsating heat pipes operates successfully for high heat fluxes. The lateral grooves reduced the thermal resistance, being principally efficient in lower loads. Besides that, the novel channel considerably anticipated the operation startup. Therefore, a much better performance was obtained by the grooved channel PHP, which was constructed from a simple, low cost modification of the fabrication process.

Keywords: pulsating heat pipe, thermal performance, high heat flux, grooves

\section{Greek symbols}

$\phi \quad$ diameter, $\mathrm{mm}$

\section{Subscripts}

$\begin{array}{ll}\text { cond } & \text { condenser } \\ \text { evap } & \text { evaporator } \\ \text { adiab } & \text { adiabatic } \\ \text { grooved } & \text { grooved channel } \\ \text { round } & \text { round channel }\end{array}$

The continue upgrade of high-performance electronic components increases the heat generation during their operation. To guarantee a minimum lifespan degradation of these devices, new heat removal technologies are required. From that, heat exchangers with higher performance must be explored. A new technology, the pulsating heat pipe (PHP), first patented in the early 1990s by Akachi (1990) is among those that can fulfill these industry requirements. It consists of an evacuated small diameter tube with a working fluid that operates in a closed two-phase chaotic cycle. Besides being a high efficiency heat exchanger device, it has promising advantages such as flexibility, low costs, and reliability. A PHP operates in a closed two-phase chaotic and pulsating cycle, due to the particular internal arrangement of the channel, associated with the continuous phase change phenomena and the fluid confinement. A sketch of the operation principle is shown in Figure 1.

To improve the thermal efficiency, several researchers have studied the effect of grooves on thermal resistance of PHP.

\section{INTRODUCTION}




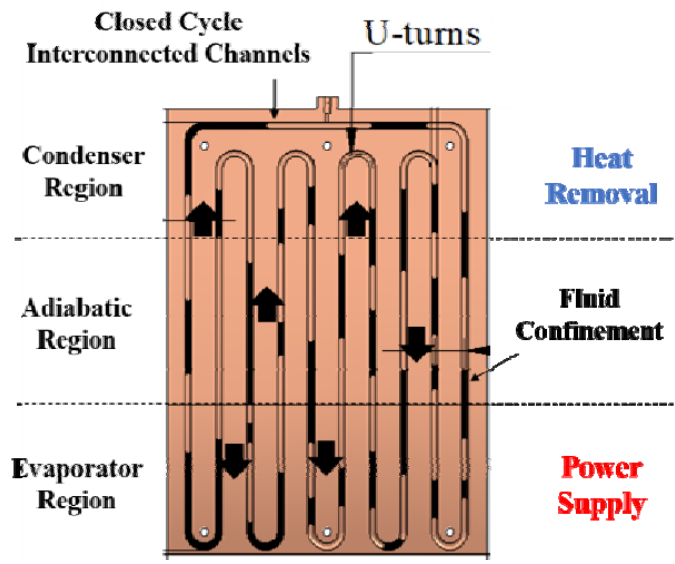

Figure 1. Sketch of a flat plate PHP operation principle.

Khan and Farjat (2011) compiled information of literature works concerning the cross-section geometry of PHPs, concluding around $50 \%$ of the works deal with square channels, followed by $30 \%$ of studies about circular channels, and the other $20 \%$ are regarding trapezoidal, triangular and other geometries. Khandekar et al. (2003) accomplished that circular channels present higher thermal resistance when compared to rectangular ones. The main reason for this behavior is the capillarity provided by channel edges. The same conclusion was found by Facin et al. (2018) and Betancur-Arboleta et al. (2020). However, the mechanical deformation of the cross-section of pulsating heat pipes with rectangular geometry are larger than the circular ones, due to the fabrication process and usual operational working fluid pressure, lower than the environment.

In this context, some researchers propose the use of grooves to improve the thermal performance of PHPs. Cai et al. (2006) verified that the microstructural groove reduces the evaporator temperature fluctuations, allowing high effective thermal conductivity. Channels with different geometries are also studied by Qu et al. (2017) and Kim and Kim (2018).

The purpose of this study is to evaluate the thermal performance of a flat plate PHP with a new evaporator channel geometry, composed by round cross section channel and lateral grooves, for high heat flux applications. An experimental analysis of this PHP was performed in vertical position and under heat loads from 20 up to $2000 \mathrm{~W}$. The results were compared with round cross section PHP.

\section{METHODOLOGY}

Two flat plate PHPs, made of copper plate with a total length of $208 \mathrm{~mm}$ and a width of $150 \mathrm{~mm}$, are shown in Figure 2. Diffusion bonding technology was used to manufacture the PHPs. More information about this process is presented in Betancur-Arboleta et al. (2020). Distilled water was used as the working fluid with a filling ratio (FR - the volume of liquid over the total internal volume of the channels) of $50 \%$, which corresponds to $17.90 \mathrm{ml}$. Preliminary tests showed this FR has the best thermal performance for this configuration of PHP.

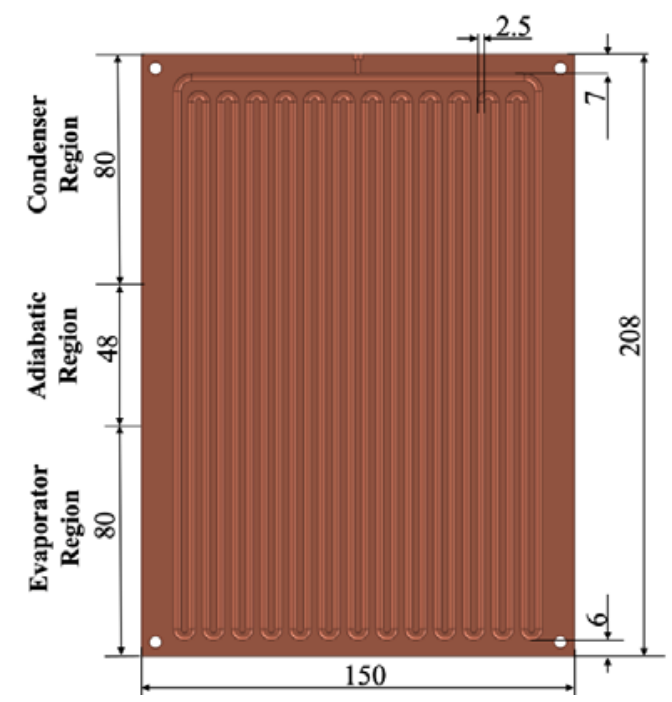

Figure 2. Schematic design of the PHPs.

\section{Channel geometry of the PHPs}

The PHPs were fabricated by two superposed plates with 26 parallel semicircular channels (13 Uturns) with a diameter of $2.5 \mathrm{~mm}$. Two different types of cross-section geometries in the evaporator section were selected for testing. Basically, the cross-section geometry of the tested PHPs is round (Figure 3a), but, for one of them, two lateral grooves are provided (Figure $3 b$ ) at the interface between the plates, at the evaporator zone. This last geometry is new. The idea is to create edges that work as capillary media that is able to keep working fluid along the whole evaporator.

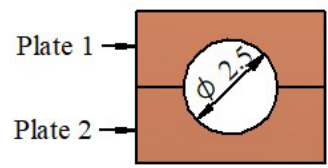

a) Round channel

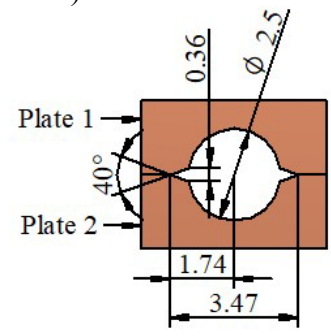

b) Grooved channel 
Figure 3. Sketch images of the channel's profiles in the evaporator (Betancur-Arboleda et al., 2020).

The fabrication process of this new configuration is very simple: chamfers of $20^{\circ}$ angles are drilled at the corners of the semicircular grooves in both plates, before the diffusion bonding process takes place, resulting in grooves of $40^{\circ}$ of angle and an opening (mouth) of 0.36 $\mathrm{mm}$ of dimension. The micro-scale images of the circular and grooved channels obtained by Secondary Electron (SE) in Scanning Electron Microscope (Jeol ${ }^{\mathrm{TM}} \mathrm{JSM}-6390 \mathrm{LV}$ ) are shown in Figure 4a and Figure 4b, respectively.

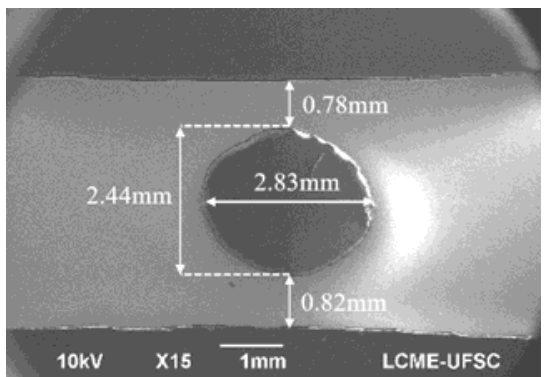

a) Round channel

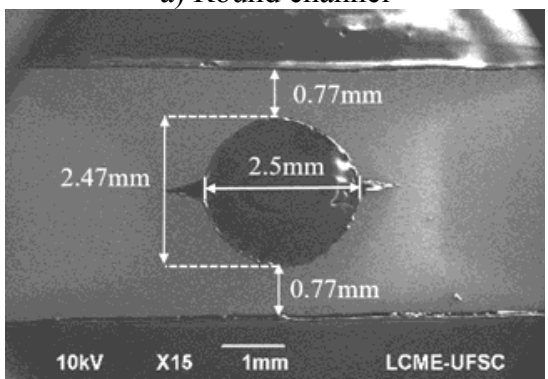

b) Grooved channel

Figure 4. SEM images of the channel's profiles in evaporator (Betancur-Arboleda et al., 2020).

\section{Experimental apparatus}

The experimental apparatus used for the experimental tests, shown in Figure 5, is composed of a programmable power source (TDK-Lambda ${ }^{\mathrm{TM}}$ GEN300-17), data acquisition system (DAQ-NI ${ }^{\mathrm{TM}}$ SCXI-1000), a Dell ${ }^{\mathrm{TM}}$ laptop, a thermal bath (Lauda Proline ${ }^{\mathrm{TM}}$ RP1845) and T-type thermocouples (Omega Engineering ${ }^{\mathrm{TM}}$ ).

The experimental apparatus should be able to guarantee that the electrical resistance supplies the heat to the evaporator, which is removed by the heat sink on the condenser. The PHPs present an evaporator region of $80 \mathrm{~mm}$ in length, an adiabatic region of $48 \mathrm{~mm}$ and a condensation region of 80 $\mathrm{mm}$. In the evaporator, a programmable power source TDK-Lambda GEN300-17 supplies energy to eight cartridge electrical resistances $(10 \mathrm{~mm}$ of diameter and $100 \mathrm{~mm}$ of length) embedded on copper block (140 mm x $20 \mathrm{~mm})$. Each electrical resistance can provide up to $320 \mathrm{~W}$. The total evaporator contact area is $22,400 \mathrm{~mm}^{2}$. The condenser is composed of an aluminum block $(140 \mathrm{~mm} \times 80 \mathrm{~mm})$ with a heat exchange area of $11,200 \mathrm{~mm}^{2}$. The condenser block consists of two parallel channels for water flow, which temperature is controlled by thermal bath Lauda Proline RP1845 of $20 \mathrm{l} / \mathrm{min}$. Thermal grease Omegatherm $^{\mathrm{TM}} 201$ was used to reduce the contact resistance. To prevent losses to the external ambient, the entire test section is isolated with ceramic fiber blanket with a thickness of $20 \mathrm{~mm}$.

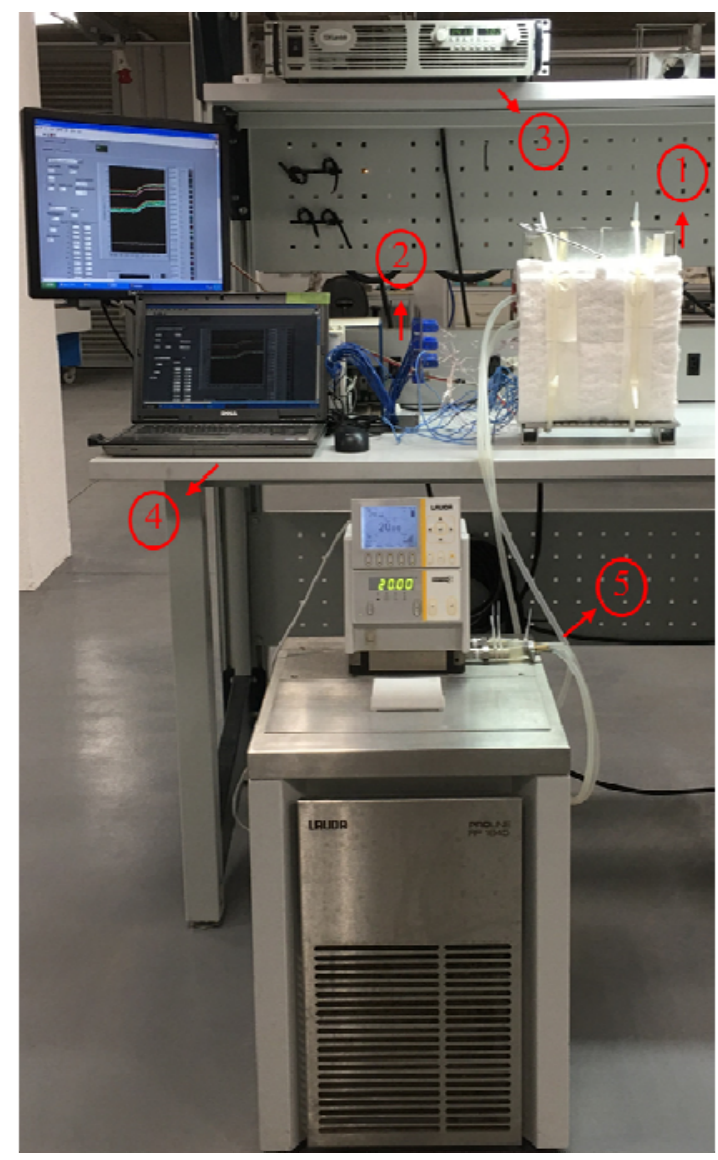

Figure 5. Experimental apparatus. 1) PHP; 2) Data acquisition; 3) Power source; 4) Computer; 5) Thermal bath.

An adiabatic section is provided between the evaporator and the condenser. A scheme of the PHP sections and experimental setup is presented in Figure 6 and Figure 7, respectively.

For the evaluation of the thermal performance of the heat pipes, fourteen T-type thermocouples Omega Engineering ${ }^{\mathrm{TM}}$, connected to DAQ-NI ${ }^{\mathrm{TM}}$ SCXI-1000 data acquisition system, were used. The maximum error of the thermocouples is $\pm 0.3{ }^{\circ} \mathrm{C}$. They were fixed on the outer surface by a thermosensitive adhesive strip Kapton ${ }^{\mathrm{TM}}$. Five thermocouples were installed in the evaporator ( $\mathrm{T}_{\text {evap }, 1}$ to $\left.\mathrm{T}_{\text {evap,5}}\right)$, three in the adiabatic section $\left(\mathrm{T}_{\text {adiab,1 }}\right.$ to $\left.T_{\text {adiab, } 3}\right)$ and five in the condenser $\left(T_{\text {cond, } 1}\right.$ to $\left.T_{\text {cond, } 5}\right)$, 
as presented in Figure 8. In addition, a thermocouple measures the ambient temperature.

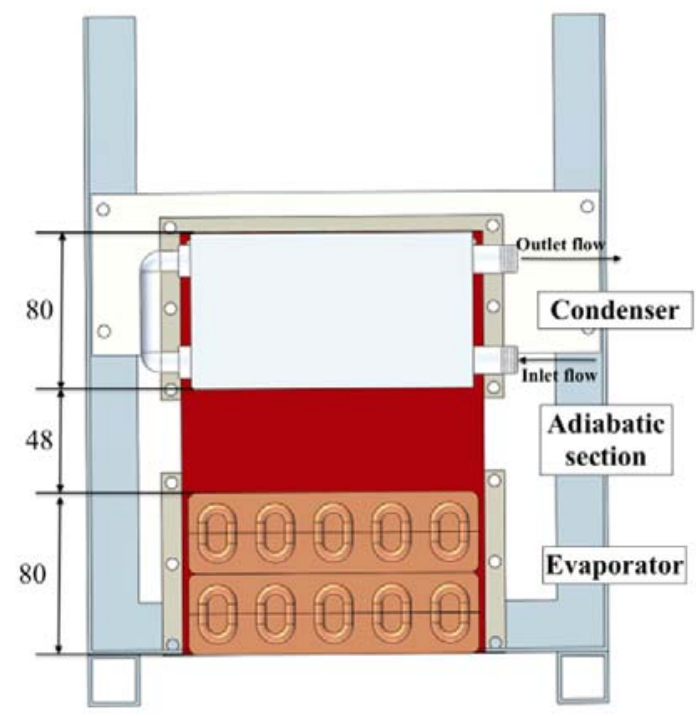

Figure 6. Scheme of the PHP sections and experimental apparatus.

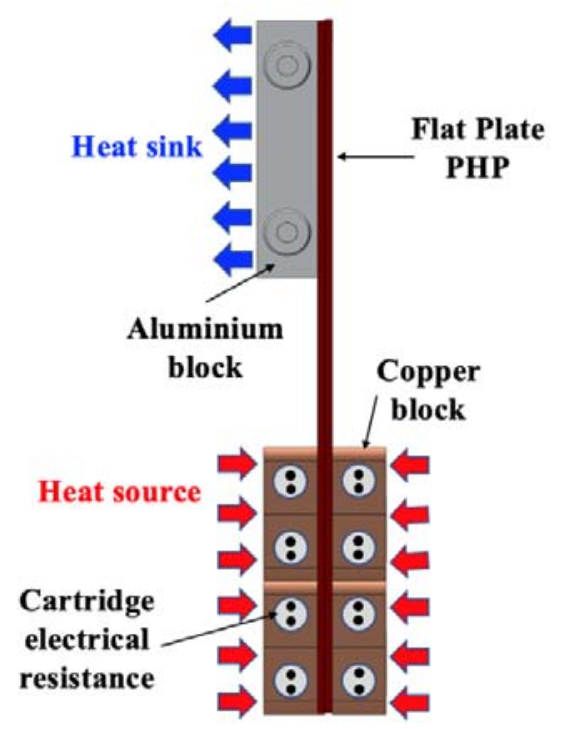

Figure 7. Scheme of the experimental setup.

For all the experiments, water flow was remained at $20{ }^{\circ} \mathrm{C}$ in the condenser. The heat loads varied from 20 up to $2000 \mathrm{~W}$. Each heat load input level was kept for $900 \mathrm{~s}$, to guarantee steady-state operation. The empty PHP presented a deviation lower than $0.3{ }^{\circ} \mathrm{C} / \mathrm{min}$. Data were acquired every at each second rate (one data per second) and recorded in a laptop with the Labview software.

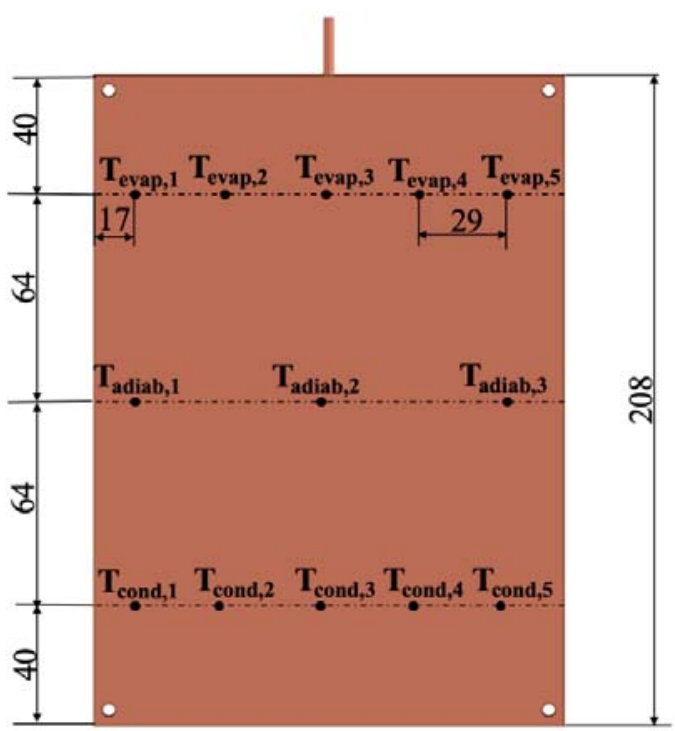

Figure 8. Thermocouples distribution of PHPs.

\section{Data Reduction}

The evaluation of the thermal performance of heat pipes can be estimated by the thermal resistance, which is defined as the ratio between the temperature difference between the evaporator and condenser regions and the dissipated power. The evaporator temperature $T_{\text {evap }}$ is the average temperature of the thermocouples located in the evaporator zone. The condenser temperature $\mathrm{T}_{\text {cond }}$ is the average temperature of the thermocouples at the condenser. The adiabatic temperature $\mathrm{T}_{\text {adiab }}$ is the average temperature of the thermocouples in the adiabatic section. Thus, the overall thermal resistance can be determined as:

$$
\mathrm{R}_{\mathrm{t}}=\frac{\overline{\mathrm{T}}_{\text {evap }}-\overline{\mathrm{T}}_{\text {cond }}}{\mathrm{q}}
$$

The experimental uncertainties are calculated using the error propagation technique (Holman, 2011). They are associated with the T-type thermocouples, the data logger, and the power supply. The average experimental temperature uncertainty was estimated at approximately \pm 0.07 ${ }^{\circ} \mathrm{C}$. The voltage and current uncertainties provided by the manufacturer are $30 \mathrm{mV}$ and $8.5 \mathrm{~mA}$, respectively. Therefore, the uncertainty of the thermal resistance was found to be $26 \%$ at $20 \mathrm{~W}$, decreasing to less than $6 \%$ at $2000 \mathrm{~W}$. The uncertainties are shown in the experimental results section. A relative difference, $\mathrm{RF} \%$, of the thermal resistance gives the improvement of the thermal performance caused by the presence of grooves in the evaporator. This parameter can be calculated with the equation: 


$$
\mathrm{RF}_{\%}=\frac{\mathrm{R}_{\mathrm{t}, \text { grooved }}-\mathrm{R}_{\mathrm{t}, \text { round }}}{\mathrm{R}_{\mathrm{t}, \text { round }}}
$$

\section{EXPERIMENTAL RESULTS}

The transient behavior of the pulsating heat pipes for power levels varying from 20 up to $2000 \mathrm{~W}$ at vertical position are shown in the Figure 9. Both PHPs work successfully and, as expected, as the dissipated power increases, the temperatures also rise.

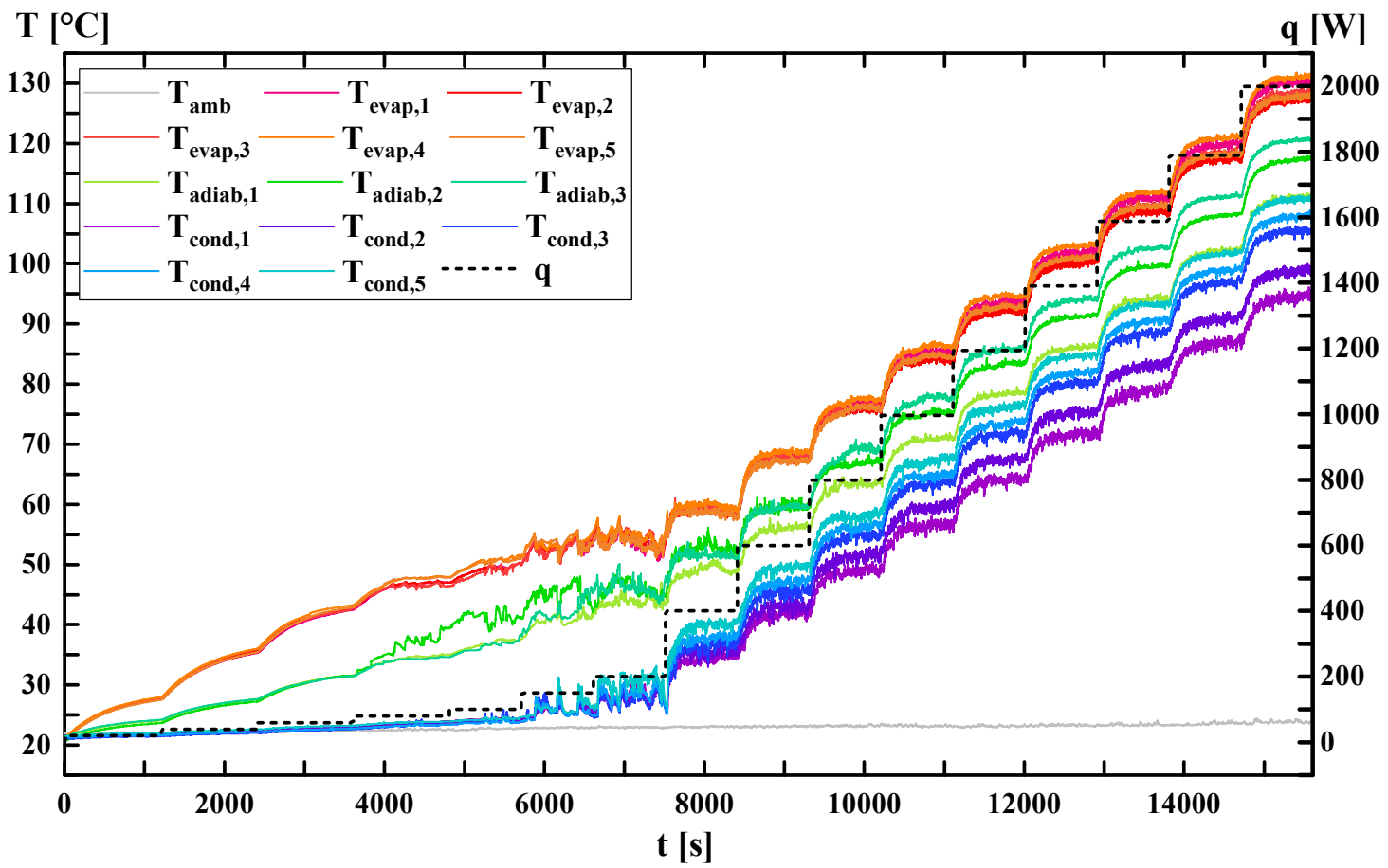

a) round channel PHP at vertical position

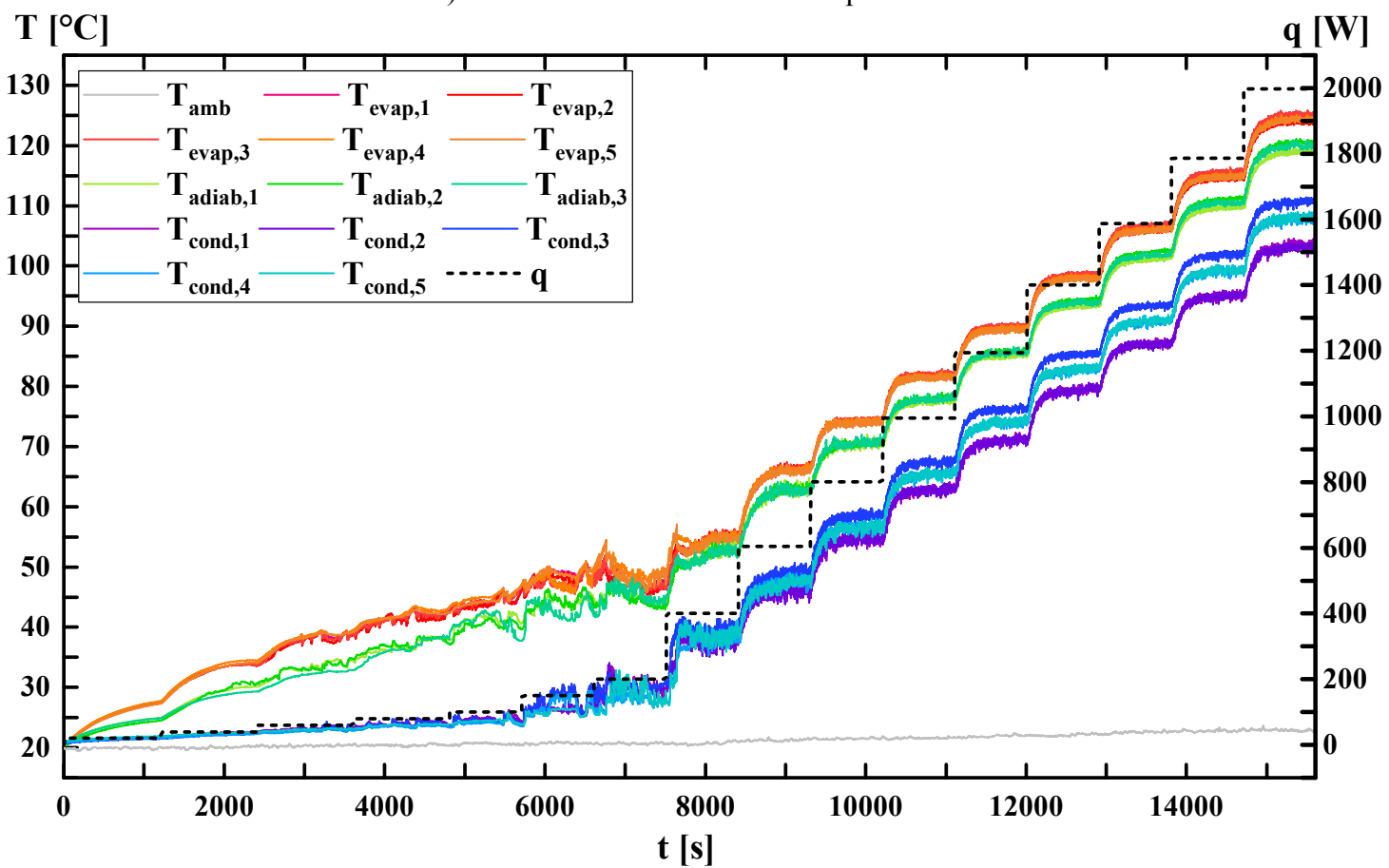

b) grooved channel PHP at vertical position

Figure 9. Transient behavior of PHPs at power levels from 20 up to $2000 \mathrm{~W}$ at vertical position and FR of $50 \%$. 
The round channel PHP, Figure 9a, shows that at $80 \mathrm{~W}$ vapor starts to leave the medium the evaporator zone and reaches the adiabatic section of one of the channels $\left(T_{a d i a b .2}\right)$. On the other hand, for the grooved PHP, Figure 9b, vapor starts to achieve the adiabatic region at just $40 \mathrm{~W}$, as same thermocouples show. Besides that, the temperature of the entire adiabatic zone reaches the evaporator temperature faster in this channel profile. The main differences in the thermal performance of the grooved PHP are related to the startup and to the uniformity of temperatures. The devices show a different head load level for the start-up, which can be observed when the vapor achieves the condenser, therefore closing the thermodynamic cycle. The round channel PHP starts at $80 \mathrm{~W}$ with an evaporator temperature of approximately $50{ }^{\circ} \mathrm{C}$, while the grooved one starts at $60 \mathrm{~W}$ with an evaporator at nearly $45{ }^{\circ} \mathrm{C}$, approximately. The grooved channel presented a greater temperature uniformity, i.e., the temperature range is smaller than the round one. As an example, for the round channel profile at $2000 \mathrm{~W}$, the temperatures variations at the evaporator are around $5{ }^{\circ} \mathrm{C}$, at the adiabatic section of $11^{\circ} \mathrm{C}$, and at the condenser of $17{ }^{\circ} \mathrm{C}$. However, for the grooved one, the evaporator, adiabatic section and condenser temperatures variations are about $3{ }^{\circ} \mathrm{C}, 2{ }^{\circ} \mathrm{C}$, and 8 ${ }^{\circ} \mathrm{C}$, respectively.

Calculating the average temperature of the PHP's sections, it is clear that the grooved PHP has lower temperature at the evaporator zone, of almost 5 ${ }^{\circ} \mathrm{C}$, and that the average temperatures of the three regions are closer. Although $5^{\circ} \mathrm{C}$ can be considered a small difference, in electronics applications this reduction can be crucial for the life cycle of the components (Lakshminarayanan V.; Sriraam N., 2014). At the adiabatic and condenser zones, the temperature is higher at the same variation. This difference is a consequence of the better operation of the grooved channel PHP. The average temperature of all sections of the PHP are shown in the Figure 10.

The thermal resistance is a very interesting parameter that can show the capacity of the tube in transporting more heat using two-phase heat exchange mechanism, being defined by Eq. (1). Figure 11 presents the thermal resistance of both PHPs. According to this figure, the thermal resistance of the grooved PHP is smaller than the round one, for every heat load, which means that the grooves improve the device heat transfer capability. Also, the startup can be observed in the Figure 11 by the sudden decrease of the thermal resistance.

Figure 12 presents the relative difference (percentage) of the improvement (RF [\%]) in thermal resistance using lateral grooves (see Eq. (2)), which is clearly for all the dissipated power applied. The thermal resistance of the round PHP with grooves decreases at least $10 \%$, when compared to the round $\mathrm{PHP}$, for powers between $40 \mathrm{~W}$ and $2000 \mathrm{~W}$.

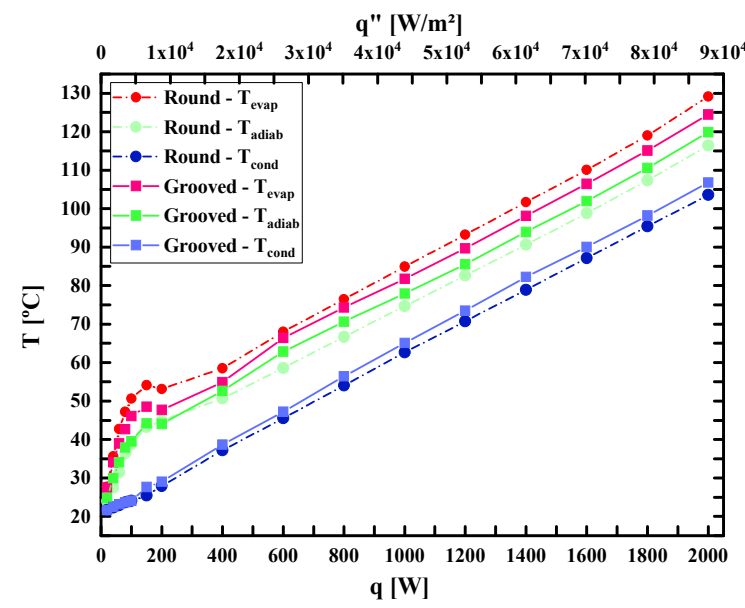

Figure 10. Average temperature of the evaporator zone $\left(\mathrm{T}_{\text {evap }}\right)$, adiabatic section $\left(\mathrm{T}_{\text {adiab }}\right)$ and condenser zone $\left(\mathrm{T}_{\text {cond }}\right)$ for different heat loads.

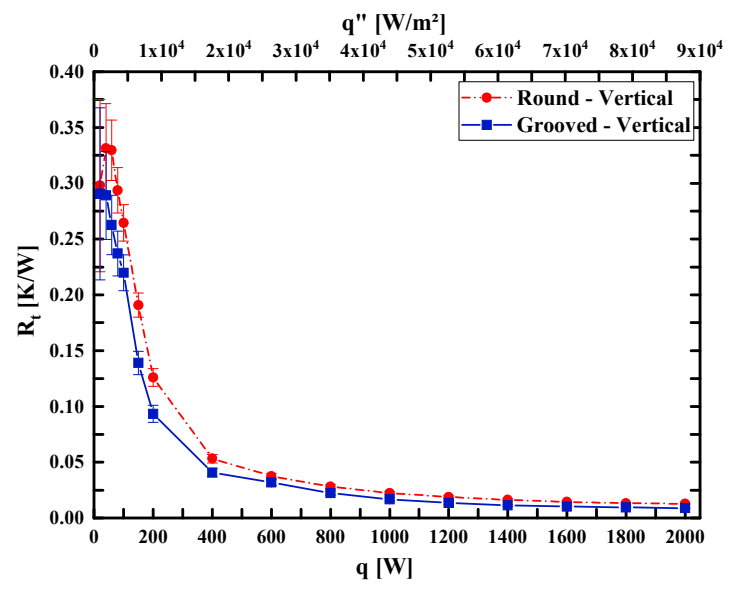

Figure 11. Thermal resistance of the PHPs at vertical position with FR 50\%.

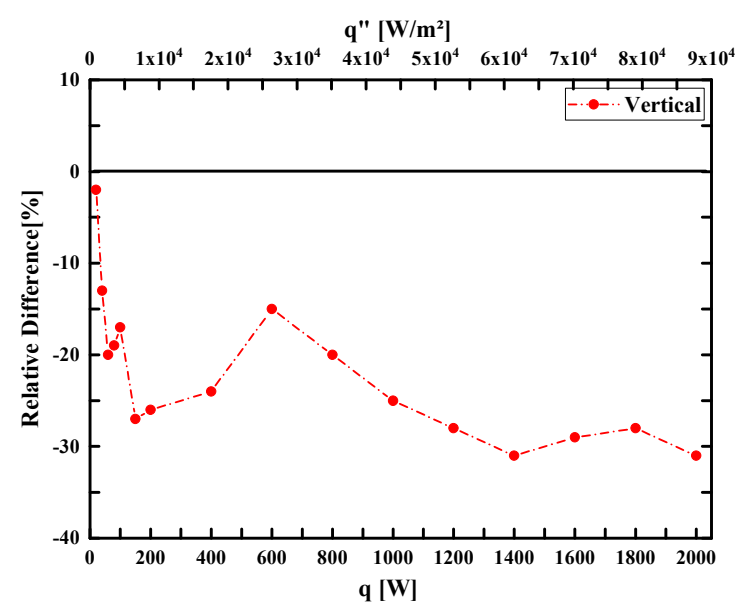

Figure 12. Relative difference (percentage) of improvement in the thermal resistance of the PHPs at vertical position with FR 50\%. 
After the PHP activation, the slope of the curves for the grooved and round channel devices follows a similar trend. Even though, the grooved PHP always showed a better thermal performance. Close to 600 $\mathrm{W}$, one can conclude that both of them has the same thermal resistance, which is in agreement with literature remarks (Kim; Kim, 2018), which highlights that grooves have higher influence at lower powers.

\section{CONCLUSION}

In this paper, two flat plate pulsating heat pipes with 26 channels were experimental evaluated for high flux applications in the vertical position. The heat loads varied from 20 up to $2000 \mathrm{~W}$. One of the PHPs has grooves in the evaporator region, obtained by a simple to machine lateral chamfers in the sharp corners of the grooved plates. The conclusions are:

- Both PHPs work successfully and as expected, as the dissipated power increases, the temperatures also rise, and the thermal resistances reduce.

- The main differences in the thermal performance between the grooved PHP and the round one is related to the startup and uniformity of temperatures.

- The round channel has a later startup when compared to the grooved profile.

- The grooves reduced the temperature variation within each section.

- After the PHP activation, the slope of the curves for the grooved and round channel devices follows a similar trend.

- The grooved PHP always showed a better thermal performance with a lower thermal resistance.

Concluding, one can say that a simple modification in the channel geometry results in a considerable thermal enhancement of the flat plate pulsating heat pipe operating in vertical position. This means that grooved PHPs are convenient for lower heat loads, as they start-up at lower power levels and as, in high fluxes, both devices demonstrate similar efficiencies. Further studies are necessary to explore the groove effect at different filling ratios and the devices operating at positions against gravity.

\section{ACKNOWLEDGEMENTS}

Acknowledgments are provided to the $\mathrm{CNPq}$ (Conselho Nacional de Desenvolvimento Científico e Tecnológico) and the UFSC (Universidade Federal de Santa Catarina) for their support.

\section{REFERENCES}

Akachi, H., 1990, Structure of a Heat Pipe, US Patent, No. 4,921,041.

Betancur-Arboleda, L., Hulse, P., Melian, I., Mantelli, M., 2020, Diffusion-bonded pulsating heat pipes: fabrication study and new channel proposal,
Journal of the Brazilian Society of Mechanical Sciences and Engineering, Vol. 42, No. 9.

Cai, Q.; Chen, C. L.; Asfia, J. F., 2006, Heat transfer enhancement of planar pulsating heat pipe device, American Society of Mechanical Engineers, Heat Transfer Division, (Publication) HTD, pp. 1-6.

Facin, A., Betancur, L., Mantelli, M., Florez, J. P., Coutinho, B. H., 2018, Influence of channel geometry on diffusion bonded flat plate pulsating heat pipes, in: 19th International Heat Pipe Conference and 13th International Heat Pipe Symposium, Pisa, Italy.

Holman, J. P., 2011, Experimental methods for engineers, 8th. ed., New York, USA.

Khan, M. G.; Farjat, A., 2011, A review on microchannel heat exchangers and potential applications, International Journal of Energy Research, Vol. 35, pp. 553-582.

Khandekar, S., Charoensawan, P., Groll, M., Terdtoon, P., 2003, Closed loop pulsating heat pipes Part B: Visualization and semi-empirical modeling, Applied Thermal Engineering, Vol. 23, No. 16, pp. 2021-2033.

Kim, W.; Kim, S. J., 2018, Effect of reentrant cavities on the thermal performance of a pulsating heat pipe, Applied Thermal Engineering, Vol. 133, pp. 61-69.

Lakshminarayanan, V., Sriraam, N., 2014, The effect of temperature on the reliability of electronic components, in: IEEE International Conference on Electronics, Computing and Communication Technologies (CONECCT), Bangalore.

Qu, J., Li, X., Xu, Q., Wang, Q., 2017, Thermal performance comparison of oscillating heat pipes with and without helical micro-grooves, Heat and Mass Transfer/Waerme- und Stoffuebertragung, Vol. 53, No. 11, pp. 3383-3390. 